\title{
False Memories and Real Epistemic Problems
}

\author{
Steven D. Brown, University of Leicester
}

Paula Reavey, London South Bank University

\begin{abstract}
The dichotomy between 'truth' and 'falsity' in relation to memory is difficult to clearly sustain. The veridicality of memory is typically established by drawing on the local, normative procedures that operate in a given setting (e.g. legal, clinical, social). Since all procedures are strictly relative, all memories are technically either 'relatively falsified' or 'relatively as-yet-unfalsified'. False Memory Studies claim to be able explain the production of false memories, but do not offer criterion to effectively differentiate populations of so-called 'true' and 'false' victims. The narrative of the discovery of the 'false memories' themselves is inconsistent and demonstrates a significant level of imagination inflation and suggestibility to dominant narratives in post-war Psychology. In attending to the setting-specificity of memory, researchers may wish to consider how their work impacts on the experience-ecologies to which they contribute
\end{abstract}

\section{Introduction}

A sixteen year-old young man is convicted of participating in the brutal rape and murder of woman, along with his uncle. His conviction relies, in part, on a confession he has made during the course of questioning by police investigators. He later recants on his confession. Filmed footage of the police interviews, conducted without the presence of a lawyer or family member, appear to show the investigators guiding and shaping a narrative for the young man. At times they provide crucial details that they ask him to confirm. Much of what he is taken to remember consists of agreeing with statements that are put to him.

A twenty-eight year old woman writes an open letter to a national newspaper accusing her stepfather of sexually abusing her when she was a seven year-old child. This is not the first time she has made these allegations. They originally appeared in the context of the divorce between her stepmother and stepfather. No criminal charges were brought at the time. The letter followed the publicity around a professional award given to her stepfather, a well-known public figure. The woman seeks to make plain what she sees as a very different side to the man, which has, she claims, been deliberately and systematically ignored by his peers.

A young man in his early twenties is shown a picture by a psychologist that shows him as a child taking part in a hot air balloon ride and asked what he can remember of the event. The photograph is a fake, which has been digitally constructed out of real photographs provided by the man's parent. The man initially claims not to remember anything about that day. But under the structured guidance of the psychologist, they gradually assemble some details. Over a series of interviews, these details are carefully pulled together to form a narrative of an event that, to the best knowledge of both the man and his parent, did not actually occur. 
What do these three vignettes have in common? What do they tell us about memory and the process of remembering? The first comes from the case of Brendan Dassey, featured in the documentary Making a Murderer, which focuses on the case against his uncle Steven Avery around the murder of Teresa Halbach. The second describes the allegations publicly made by Dylan Farrow about her stepfather Woody Allen. The third is taken from the description of an experiment conducted by Kimberley Wade and colleagues at Victoria University of Wellington (Wade, Garry, Read \& Lindsay, 2002). Three very different sets of events, taking place at different times and places, and under vastly different circumstances. Yet all appear to suggest something about the complex and contested relationship between what is remembered and the nature or indeed the existence of the actual events themselves. They suggest the possibility of 'false memory'.

Or at least, that is one interpretation. Here are some others. Each of these cases occurs when the person concerned interacts with some form of institutional practice (i.e. the judicial system, the media, university based research). What is remembered takes place following the person being confronted with evidence or propositions (i.e. accusations, solicitations, implicit suggestions) that they either do not entirely understand or which are outside of their control, due to their status as either a vulnerable adult, a self-identified 'survivor', or being confronted with scientific 'expertise'. The power to manage and control the situation clearly lies with the institution and its representatives (i.e. investigators, reporters, experimenters) in a way that is tangible to the participants.

Alternatively, another thread running through all the cases is the actual or suspected betrayal of the person by a close family member. In Brendan Dassey's case, it is the suspected actions of his uncle that have led to him to be taken from school into the bewildering and threatening atmosphere of the criminal justice system. For Dylan Farrow, the central felt betrayal concerns her stepfather, which is then compounded, for her, by refusal of his peers - some of whom she knows personally - to take her allegations seriously. And although the stakes are somewhat different for the participants in Wade's experiments, the alternatives before them are to either accept that their own memory is at fault or to confront the challenging and perplexing idea that their parent would collude with an hitherto unknown professional to create a situation where they would be potentially embarrassed or humiliated.

Finally, what all of these cases show us is the fraught relationship we all have to the past that we strive to remember. The central problem in the Steven Avery case is that the details of what actually happened in the murder of Teresa Halbach have become less rather than more clear in the course of huge efforts to secure and maintain a conviction. Brendan's memories have been subject to repeated construction and deconstruction by the legal-investigative processes in which he is caught up, with the result that at the time of writing his conviction had been overturned Federal Court. Similarly, Dylan's recollection has been the object of contestation through a whole series of subsequent events and public conflicts (e.g. her step-parents divorce and the ensuing publicity). Whilst Wade's participants have not had to endure such dramatic circumstances, their pasts are 
no less uncertain. Perhaps there really was a balloon ride that went undocumented and has been forgotten by the parents. Or perhaps entertaining uncertainty around this event threatens to corrode the memorial scaffolding on which their family relationships are built.

Taking any of these three cases as exemplars for a clear dichotomy between 'truth' and 'falsity' in memory seems rather problematic. The question we want to open up in this paper is what is actually accomplished through the use of the term 'false memory'. How does this term enhance our understanding of the situated and contextual dynamics wherein the past is collaboratively invoked and put to work in the present. After all, as Elizabeth Loftus, one of the key contributors to the field has observed - 'In essence, all memory is false to some degree' (Bernstein \& Loftus, 2009, p.373). Our argument is that rather than bringing us closer to the practices where recollections are offered and contested, the notion of false memory actually estranges and displaces the things we would want to understand. We call instead for an attention to the setting-specificity of remembering, where memory is approached as a property of jointly-managed activities that occur in a definite time and place, and which have their own distinct norms and procedures as to what constitutes 'truth' and 'falsity' (see Brown \& Reavey, 2015). Applying this approach to the psychology of memory itself allows us to reflexively question the complex relationship that psychologists have to the history of the discipline in which they are formed and located.

\section{Relatively Falsified Memories}

A good starting place is with the distinction between truth and falsity on which the conceptualization of 'false memory' stands. As commonsense, everyday terms, 'true' and 'false' are used a huge variety of ways. We can point to just a few of these to demonstrate. As technical terms, they mark whether a prior statement fits within what is taken to be the legitimate frame of reference ('that is a false'). As rhetorical terms, they indicate the extent to which there is an alignment of opinion between speakers ('what you say is true insofar as...'). As ethical terms, they indicate whether there is a proper moral continuity expressed in the actions of someone or something ('a false prophet'). And as political terms they express a desire to unwind ideology from perception or debate ('speaking truth to power). Clearly there are many other usages.

Because of the inherent diversity and contradictions in usage, it is important to be clear on just what 'false' means in relation to memory. Presumably this falls somewhere within the technical domain. A false memory is one that deviates from the range of expected accounts of some given prior event. But this merely displaces the judgment, since it then requires us to properly state how these 'expected accounts' were arrived at, what forms of evidence are deemed to be relevant and the procedures that were used to evaluate them. So whilst 'truth' and 'false' are the commonsense terms used in delivering this verdict, the judgment itself refers to a normative application of prior criterion and standards. Moreover, since access to the full range of historical data on which a given recollection is based may typically not be available (think again of whether or 
not we are able to say definitively that a given event did or did not happen), then the normative judgment is tentative and provisional.

This way of thinking about truth resonates with what the philosopher Martin Heidegger (2013) referred to as 'correctness'. For example, the statement 'this is true gold' does not express anything of the essential nature of what gold is, but rather reflects a normative judgment based on whatever criterion are in play within the practice where the statement is uttered. 'True gold' for the merchant or the banker may be established by procedures such as weighing or markers of external verification (e.g. hallmarks), whereas 'true gold' for the chemist or physicist may require calculation of atomic mass and chemical testing. Referring to these matters as 'correctness' allows Heidegger to disentangle situated cultural-historical technical judgments from a broader sense of the truth. This, for Heidegger originates in the Greek term 'aletheia', which he translates as 'disclosure' or 'unconcealment' and which refers to the temporal process by which things come into appearance in the world. This process implies both that there are aspects to the world that are not given at once, but are rather emergent, and that what is disclosed depends substantially on the situated nature of our engagements with events.

This expanded version of truth has a projectful character that comes freighted with ethical commitments. It is our duty to follow truth as an always emergent, incomplete process where things are always differing from the ways in which we first encountered them. By contrast, the narrow technical version insists on a stability of identity and that things conform with the way we want them to be. It is the conflation of these two senses that allows those who would seek to impose their own technical procedures beyond the domain of their normative application to cloak themselves in the moral guise as 'defenders of truth', and conversely those who do not adhere to those procedures as 'unreliable' or 'true believers' (see Campbell, 2003).

To avoid this, we would suggest replacing the terms 'true' and 'false' with those that are better fitted to the procedural and normative aspect of judging memory. Let us be clear that we are not arguing against the possibility of establishing whether a given recollection can be judged to be sufficiently accurate or not. Quite the reverse: this matter is so crucial that we need to overcome the unhelpful allusions that attach to notions of 'truth' and 'falsity'. We propose that recollections that do not map onto normatively established criterion of correctness ought properly to be called 'relatively falsified memories', where the modifier relative refers to the situated nature of the judgment. Recollections that do pass this test are not, by default, 'true', since this implies the existence of a further set of unspecified procedures for complete verification. In the case of Wade's experiments this would amount to something like a full forensic investigation of the complete life-history of the participants which was able to eliminate beyond any reasonable doubt that no balloon ride had ever been made. Instead 'correct' memories should be termed 'as-yet-unfalsified memories'.

But to arrive at these more refined categories would require further investigation into the actual procedures for partial verification that are used in a given setting. For example, Elizabeth Loftus' well-known Lost in the Mall 
experiment (see Loftus \& Pickrell, 1995), developed the procedure later used by Wade et al of using information supplied by family members as the basis for facilitating 'false memories'. In doing so, the experimenters essentially based their falsification procedure on trust in this initial information. It seems that at no point did they question the accuracy of the family member's memories, despite the inherent mistrust of personal experience that permeates the approach. A crucial question is whether or not research of this kind is able to demonstrate that it is not vulnerable to precisely the kinds of external influences that it purports to study (see Motzkau 2009 on suggestibility research).

A further issue is with the reasoning that underpins the division of true and false. In a summary of the state of the field in 2003, Loftus claims:

Collectively, researchers have learned a great deal about how false memories develop and are almost at the point of being able to write a recipe. First, the individual gets convinced that the false event is plausible. Even events that start out being rather implausible can be made to seem more plausible by simple suggestion. Next, the individual gets convinced that the false event was personally experienced. Plying the person with false feedback is a particularly effectively way to accomplish this. At this point, the individual might merely believe that the event is true but have no sense of recollection. But with guided imagination, with visualization of the stories of others, and with suggestive feedback and other sorts of manipulation, a rich false memory can occur. (Loftus, 2003, p.871)

This seems at first glance quite a promising model. Constructing plausibility creates the fertile field in which additional misinformation can take hold, which is then elaborated by adding visualization and suggested perceptual experiences resulted in the ultimate implantation of a 'rich false memory'. However, the sorts of target 'false memories' which have been the longstanding object of the field, and indeed the source of the term 'false memory' in the first place, are those where adults remember extreme, traumatic experiences, typically of rape or sexual violence during childhood that are subsequently not verified through legal or other procedures (or may sometimes be retracted) (Campbell, 2003). It must be said that these kinds of cases are comparatively rare when set against the number of cases where some form of verification is possible, and the further 'file drawer' set of cases that are never brought because of concerns around the legal process. The Loftus model seeks to explain this small number of cases by beginning with a far broader general population and then probabilistically states how, from an initial condition, each step may lead to the formation of a false memory.

The trouble with this kind of reasoning is that it overlooks the conditional probabilities that are involved. If one were really committed to understanding the difference between what Loftus (2003, p.871) calls 'false victims' and 'true victims', then properly speaking the approach ought to be 'given the existence of an allegation of abuse, what factors distinguish the classes of 'true' and 'false'?' rather than 'what factors lead probabilistically from initial conditions to the final outcome?'. The difference between these approaches is significant, in both a logical and a statistical sense. The approach taken in false memory research 
starts with the general and tries to work its way down a quasi-causal pathway to the particular. Whereas beginning from actually occurring events, defining discrete populations around those events and looking to factors that distinguish those populations from one another eliminates much speculative reasoning.

For example, in the previous citation, Loftus draws upon a mélange of ideas to build a conceptual bridge from the general to the particular, including the misinformation paradigm, imagination inflation, suggestibility research, guided imagery/vizualisation studies and more. But even this heavily over-egged theoretical recipe can't quite reach its intended target because, crucially, at no point is it able to show the actual implantation of memories of childhood sexual abuse. These are probabilistically implied rather than demonstrated. So strictly speaking we must say that what is being studied is not the same thing as a 'false memory of childhood abuse'. But if the research were to begin with the actual joint occurrence of allegations of abuse with either support or falsification, then meaningful questions as to whether, say, 'imagination inflation' distinguished the actual populations - and therefore had any explanatory value at all - could be posed. It is our suspicion that very little of what is in Loftus' recipe would differentiate the populations, and that other factors such as history of engagement with social-welfare services, social and economic conditions or copresence of other forms of emotional abuse, might be better candidates.

\section{The Formation of False Memory Research}

So if false memory research does not actually demonstrate the implantation of 'false memories of child sexual abuse', then what can we say about what it does show and the way it arrives at those demonstrations? As befitting someone who is now at the apex of their career, Loftus has published numerous overviews of the development of the field and the centrality of her role (e.g. Loftus, 2013; Loftus, 2000; Loftus \& Ketcham, 1995). The narrative typically begins with her well-known work on eyewitness memory in the 1970s, which established experimentally the power of providing misinformation on subsequent recall of films of traffic accidents (see Loftus, 1979). This work occurs at a pivotal point in the recent history of psychology. It is the moment where the cognitive paradigm is beginning to achieve a degree of systematization, pulling together parts of information theory with systems theory, cybernetics and analytical philosophy. Dupuy (2000) has argued that the particular way in which cybernetics was mobilized was decisive. Analytical approaches from philosophy of mind became wedded to the approach, with the effect of erasing questions of reasons and meaning. Difficult philosophical notions such as intentionality became operationalized in a reductive manner as matters of feedback and information processing, following Weiner's (1948) original proposed solution. The outcome is what Dupuy calls a 'mechanization' of the mind.

Loftus' work embraced this mechanization in the case of memory, since it holds out the possibility of not simply representing the processes putatively involved, but also of enabling intervention. A mechanized mind is also one that is malleable. The particular form of intervention that Loftus envisaged was in relation to the law. Her working assumption at the time appears to be that since the justice system requires confidence in the testimony provided by witnesses, it is the role 
of the psychologist to demonstrate the conditions under which that confidence might be undermined through phenomenon such as suggestion, misinformation, distortion etc (see Loftus \& Ketcham, 1992). This is a somewhat peculiar way of posing the problem - surely questions of justice are better formed in terms of recognizing how to elicit and recognize those things and persons who stand in need of reparation? That is, how to create rather than dissolve confidence in legal testimony. Loftus' initial orientation to this problem makes clear why much of her work makes reference to the tradition of 'skepticism'. However, what is missing here is an awareness that historically skepticism emerged out of a critique of existing authorities and power - it is a weapon of the weak that uses reason against brute force, not a further cudgel through which the powerful can further buttress themselves against potential claimants (see Stengers, 2000)

The use of skepticism as a means of supporting rather than critiquing existing social and/or political arrangements certainly fits with how some dialects of psychology, particularly in the USA, have seen the role of the discipline post1945. Nevertheless, it is extraordinary to propose, as Loftus has done recently, that a legitimate application of false memory research would be to engage in the of implanting false memories in order to influence dietary choices as part of a social programme against the 'obesity epidemic' (Bernstein, Pernat and Loftus, 2011). Even when her work has identified with a 'vulnerable' group, such as families accused of historical sexual abuse by adult children (e.g. members of the False Memory Syndrome Foundation), the strategy has been to support their efforts to dismiss the claims made against them by those who identify as victims rather than attempting to understand the material and psychological conditions under which a family might collapse into serious open conflict.

Critics of the kind of experimental psychology of memory that Loftus has pioneered typically bemoan its obsession with accuracy rather than with the contexts in which remembering occurs (e.g. Middleton \& Brown, 2005). But in actuality, accuracy is never really the concern in false memory research - the focus is on the impairment of accuracy, or the production of error. Because of this, there is little to be found in this work that assists in the project of improving confidence in memory, of supporting the vulnerable in making sense of what they remember. Arguably, the participants in a variant of the Lost in the Mall or the Fake Balloon Ride study don't really learn anything that would help them in relation to their own autobiographical memories, other than not to trust either experimental psychologists or their own family members.

One possibility here might be to see that many of the problems stem from what Dupuy (2000) calls the 'unhappy accident' where psychologists bought into the wrong combination of cybernetics and philosophy. Consider, for example, the kind of speculative theories of alcoholism and 'schizophrenia' that Gregory Bateson (1973) - one of the key figures in the Macy conferences which became the foundations of modern cognitive science - developed by taking an 'open systems' version of cybernetics rather than a 'closed systems'. Here the unit of analysis is the family or the group rather than the individual, and the processes allow for both learning and a transformation of the functioning of the system itself. False memory research is blind to these open system properties. It assumes that individuals find themselves, for whatever reason, in some situation 
where they are exposed to suggestive misinformation, which they then incorporate into their autobiographical memories. But very rarely do we simply 'arrive' in some setting without a set of intentions or projects which are relevant to what we will do next. Moreover, the 'implantation' paradigm requires that the person actively participate in the practice and perform work on themselves. To do this requires a reflexive orientation to the sort of person one is and what one wants to become.

It is the focus on the capacity for turning around on oneself, in concert with others, that is sorely lacking in false memory research. The following words of Bartlett have often been cited by those arguing for a reconstructive (rather than reproductive) conception of memory:

In a world of constantly changing environment, literal recall is extraordinarily unimportant. (Bartlett, 1932, p.203-4)

This is usually glossed as a claim for the relative lack of importance of accuracy in recall, in favour of a social orientation to remembering (e.g. Middleton \& Brown, 2005). But the full passage in which these words appear prove far more instructive:

An organism which possesses so many avenues of sensory response as man's, and which lives in intimate social relationship with numberless other organisms of the same kind, must find some way in which it can break up this chronological order and rove more or less at will in any order over the events which have built up its present momentary 'schemata'. It must find a way of being dominantly determined, not by the immediately preceding reaction, or experience, but by some reaction or experience more remote ... We must, then, consider what does actually happen more often than not when we say what we remember. The first notion to get rid of is that memory is primarily or literally reduplicative, or reproductive. In a world of constantly changing environment, literal recall is extraordinarily unimportant. (Bartlett, 1932, p.203-4)

We take Bartlett to be arguing here that a reflexive orientation to what we can remember is a means of 'breaking' with the apparent 'order' of the present through using the past as a means of restructuring our relations to others and the broader environment. To put this in systems theory terms, memory enables a kind of learning that allows the system to overcome its own parameters and achieve a new state that is not simply predictable from the current state.

The standard narrative in false memory research is that a person somehow finds himself or herself in therapy, where they are exposed to malicious practices that result in the implantation of 'false memories of childhood sexual abuse' leading them to accuse innocent family members. Yet the decision to enter therapy already indicates that this person has begun to turn around on their own life history and is seeking to find some way of 'breaking up the chronological order' to transform themselves. They do this crucially not as a wholly independent, autonomous agent (like a closed system lacking in meaning, intentions and history), but rather as a person embedded in a web of relations that together form an open system. In a small number of cases, clients do indeed claim to 
remember forgotten episodes of abuse and confront family members. But the idea of memory 'implantation' is not only unlikely to differentiate this small subset from the broader population of clients who remember childhood sexual abuse, it also doesn't really assist in understanding the particular, contingent life-histories that are implicated in cases of 'relatively-falsified memories'. Studies of 'recovered memory' have shown that there are very few incidences of remembering such events with absolutely no existing memories or suspicions of some form of abuse prior to therapy (see Reavey \& Warner, 2003). It is therefore not simply a question of switching from one form of belief ('I am unhappy') to another ('I am a victim of child sexual abuse') as a consequence of memory implantation or whatever else. To use the parallel example of Brendan Dassey, he seems to have been aware during the process of his conviction, that what he remembered in one setting (e.g. under police interrogation) was very different to what he remembered in other settings (e.g. talking to his mother). His problem then became that of managing the tensions and contradictions between the various accounts. That is to say, an ecological and relational problem grounded in the various settings in which his memories were being solicited and contested.

We can now differentiate two different ways of thinking about the 'falsity' of memory. In the first, memory is property of a mechanised mind which processes information from the environment to arrive at states that we can call 'beliefs' that determine action. The capacity of this closed system to understand the relationship between information and belief states - i.e self-insight - is somewhat limited, hence it is malleable to external manipulation. In the second, memory is the property of an open system that strives to alter its relationship to the environment by reflexively turning around on its own prior states in order to free itself from being constrained by immediate demands and conditions. When a person recalls something, they do so as part of an open system such that what is remembered is, properly speaking, the collaborative product of the system rather than the output of an individual cognitive system. In the first mode of thought, falseness is a belief state that is externally unverifiable and which is arrived at through information distortion. In the second, falseness is a complex contingent process which emerges through a reflexive effort at transforming the existing state of the system and which serves as the means for 'learning' to occur.

This differentiation of modes of thought can be usefully applied to the history of false memory research itself. Scientific research can be treated as the accumulation of more information, some of it 'correct', other parts 'false'. The processing of this information results in states we can call 'theories' or 'paradigms'. At certain historical points, the limitations of the system to include specific kinds of environmental information, or to generate novelty, brings about a crisis in the form of a system re-boot or shift to a new paradigm. This is more or less the narrative that Loftus offers in her reviews - the successive gathering of more data, more conceptual pieces of the puzzle, until the 'recipe' for making false memories gradually emerges.

But there are some significant gaps in this story. Things don't always add up. For one, there is the curious relationship that Loftus' work has to Freudian psychoanalysis (the very exemplar of unscientific 'true belief' that false memory research rejects) (see Pope, 1995). Throughout her work, Loftus has relied upon 
neo-Freudian notions of repression and suggestion to explain how nonconscious processes may be manipulated. Whilst these are usually translated into the argot of information theory, their roots to a very different tradition of practice and enquiry remain. Equally intriguing is the genesis of the term 'false memory' itself. As Pezdek \& Lam (2007) have shown, the term gains some currency within the experimental psychological community in the 1990s. Whilst conceptually much of the work that emerges there is indebted to the longstanding tradition of suggestibility research (see Motzkau 2009), the idea of a thing called a 'false memory' owes more to the formation and activities of the False Memory Syndrome Foundation (FMSF) in 1992. It is this group that first defines the problem space of 'falseness' in memory in the contemporary sense of the term. It is then constituted as a social and a political category, aligned with a particular set of group interests, rather than as a 'scientific' category emerging from data, despite the here purely rhetorical use of the medical term 'syndrome'. Loftus' research in the 1990s then seeks to flesh out this socio-political category by speculatively mixing together data and concepts derived from the very different context and tradition of experimental psychology.

The difference between this way of developing research and the 'standard view' of scientific enquiry (which forms the basis for Loftus' own narrative) can be seen in the origins of both the Lost in the Mall and the Fake Balloon Ride experiments. The former apparently began its life as a thought experiment during a car journey before becoming a 'party trick', and was only actually performed under laboratory conditions quite late in its history (with very minimal data at that) (see Ashmore et al, 2005). The idea seems to be of greater importance here than the actual experiment. Whilst the Fake Balloon Ride experiment does offer a more substantive dataset, it too appears to be a thought experiment that was waiting for the right conditions to be demonstrated rather than provoked by need to make sense of an emergent empirical problem, based on the acknowledgement 'we also thank ... Jacquie Pickrell (for her work on a pilot version of this method several years ago when our ideas outpaced the available technology)' (Wade et al, 2002, p.597).

Things do not then really add up with the narrative of gradual accumulation of facts and concepts grounded in the careful sifting of data such that a clear explanatory category 'false memory' emerges. In fact, we would have to say that technically the idea of the discovery of 'false memory' cannot be verified by the available facts, but seems to be an imaginative elaboration of the events, which is to say, in the terms of the field, a 'false memory'. What makes more sense is to treat the field as a complex trajectory of contingent relations between the social, political and the technical, that arrives at a very partial and contested description of the contextual dynamics of memory as part of a shifting alliance between various groups of interests.

\section{Memory in the Experience Ecology}

Our description of the contingent emergence of 'false memory research' is not intended as an in-principle or external critique. We do not seek to directly evaluate this field in comparison with some rival programme of memory studies. Our critique is rather with the internal logic of the approach and with the 
application of its own standards to its particular history. If the claim is that there are things such as 'true' and 'false' memories in the world, which can be identified purely in terms of the putative psychological mechanisms that distinguish them, irrespective of the particular contexts in which they occur, then this cannot be verified by the available facts within the field. In this sense, 'false memory research' is self-falsifying, it constitutes its own critique.

However, if we look at the history of the field as a contingent and provisional set of relations, which temporarily align in different ways to make interesting, contestable and contested propositions, then this can also be mobilised as an approach to 'false memory'. Imagine what might happen if at various points in the contingent history of the field, the opposite branching were taken. For example, rather than the closed systems approach, which leads to the mechanisation of mind, what if an open systems approach had been pursued. This would result in a concern with the fluidity of relations between system and environment, or out slightly differently, with the settings in which remembering occurs rather than the individual per se. Rather than treat therapy or police investigations as sites where 'false memories' are implanted, we would instead seek to understand the particular practices through which accounts of the past are collaboratively constructed (e.g. what sorts of actions, the kinds of social technologies in play, the particular use of evidence, forms of reasoning), along with the specific criterion used to establish 'true' from 'false'. Crucially, we would also want to ask what functions and broader projects are being enacted within the setting, how it makes use of 'memory' as a means of 'breaking with the chronological order' by which it might otherwise be determined.

At the same time, we might take the different tack of asking how, within a given setting, confidence is established in relation to memory. For instance, many institutional settings have a strong orientation to their own historicity, which they seek to enshrine and display in various ways, such as through explicit narratives, iconography and even material displays (e.g. corporate museums). Becoming involved with an institution means finding that one's own biography is now intertwined with that historicity in ways that can become problematic. For example, when children enter into adoption processes, social welfare institutions effectively become the 'guardians' of their memories, which they address through practices such as life-story work (see Brown \& Reavey, 2008). We would then want to ask how memory can be supported and facilitated in such settings rather than falsified.

What this amounts to is an analysis of the setting-specificity of memory. True and false are not abstract criterion which can be applied following the application of a speculative reasoning to any given case. They are instead complex, contingent matters that only have any meaning within particular setting in which they can be established (see Brown \& Reavey, 2015). We do not deny the importance of accuracy. In fact, contrary to the way that Bartlett's infamous quote has sometimes been invoked, we would say that accuracy is usually fairly decisive in the vast majority of settings. But it is always a relative term. Verification and falsification are collaborative achievements of the settings as a whole, and are typically provisional and subject to contest, since they involve matters of power 
and authority indexed to the specific projects and history of the setting (this is what all our opening three vignettes illustrate).

From this perspective, if one wanted to examine, say, why allegations of childhood sexual abuse that were relatively verified in one setting (e.g. therapy) but were relatively falsified in another (e.g. courts of law), then a reasonable empirical approach would be to take the population of allegations that were both verified and falsified in both settings (i.e. not just those that were falsified, but also those that achieved relative verification across the settings) and attempt to identify the particular, contingent factors that differentiated the two groups. This approach would, of course, have very little to say about the 'truthfulness' or 'falseness' of memory in general, but after all, if, as Loftus claims 'all memory is false to some degree', then such general claims can scarcely be of any great interest.

It is the specific conditions under which falseness and truthfulness are established which form both the empirical object, and to some extent the ethical obligations of psychological research. As Loftus rightly observes, as professionals, it is our duty to take responsibility for the life of the concepts that we develop and the effects they may have in the broader world:

mental health professionals and others must be aware of how greatly they can influence the recollection of events and of the urgent need for maintaining restraint in situations in which imagination is used as an aid in recovering presumably lost memories. (Loftus, 1997, p.75)

Psychological research is not just about the world, is is also of the world. If we think of the ranges of culturally and historically situated ways of being that are available to persons at a given place and time as constituting something like an experience-ecology (see Brown, 2015), then we can see that as responsible professionals it is our role to ensure that our ideas do not, as far as possible, pollute that ecology or become so virulent as to crowd out and destroy the other forms of cognate experience which exist within that ecology. Experiences are contingent, fragile, tentative things that sit in a web of interdependencies. We must not breed monstrous concepts that devour all before and render the ecology a barren, lifeless place.

\section{References}

Bartlett, F.C. (1932). Remembering: A study in experimental social psychology, Cambridge: Cambridge University Press.

Bateson, G. (1973). Steps towards an ecology of mind. New York: Peregrine.

Bernstein, D.M. and E.F. Loftus (2009). How to tell if a particular memory is true or false. Perspectives on Psychological Science, 4(4), 370-374.

Bernstein, D.M., N.L.M. Pernat and E.F. Loftus (2011). The False Memory Diet: False Memories alter food preferences. In V.R. Preedy et al. (eds.), Handbook of Behavior, Food and Nutrition. Berlin: Springer.

Brown, S.D. (2015). Health in the experience ecology. Psicologia della Salute 18(1), 36-41.

Brown, S.D. and P. Reavey (2015). Vital Memory and Affect: Living With a Difficult Past. London: Routledge. 
Campbell, S. (2003). Relational Remembering: Rethinking the Memory Wars. Lanham: Rowman \& Littlefield

Dupuy, J.-P. (2000). The Mechanization of the Mind: On the Origins of Cognitive Science. Princeton: Princeton University Press.

Heidegger, M. (2013). The Essence of Truth: Plato's Cave Allegory and Theaetetus. London: Bloomsbury.

Loftus, E.F. (1996). Eyewitness Testimony. $2^{\text {nd }}$ ed. Cambridge, Mass: Harvard University Press.

Loftus, E.F. (1997). Creating false memories. Scientific American, 277 (3), 70-75

Loftus, E.F. (2000). Remembering what never happened. In E. Tulving (ed) Memory, Consciousness and the Brain: The Tallin Conference. Philadelphia: Psychology Press, 106-118.Loftus, E.F. (2003). Make-believe memories. American Psychologist 58(11), 867-873.

Loftus, E.F. (2013). 25 years of eyewitness research ... finally pays off. Perspectives on Psychological Science, 8(5), 556-557.

Loftus, E.F. and Ketcham. (1992). Witness For The Defence: The Accused, The Eyewitness And The Expert Who Puts Memory On Trial. New York: St Martins.

Loftus, E.F. and K. Ketcham (1995). The Myth of Repressed Memory: False Memories and Allegations of Sexual Abuse. New York: St Martins.

Loftus, E.F. and J.E. Pickrell (1995). The formation of false memories. Psychiatric Annals 25, 720-725.

Middleton, D. and S.D. Brown (2005). The Social Psychology of Experience: Studies in Remembering and Forgetting. London: Sage.

Motzkau, J. F. (2009). Exploring the transdisciplinary trajectory of suggestibility. Subjectivity: International Journal of Critical Psychology 27, 172-194.

Pezdek, K. and S. Lam (2007). What research paradigms have cognitive psychologists used to study 'False Memory' and what are the implications of those choices? Consciousness and Cognition, 16, 2-17.

Pope, K. S. (1995)._What psychologists better know about recovered memories, research, lawsuits, and the pivotal experiment. Clinical Psychology: Science and Practice, 2, 304-315.

Reavey, P. and S. Warner ed. (2003). New Feminist Stories of Child Sexual Abuse: Sexual Scripts and Dangerous Dialogues. London: Routledge.

Stengers, I. (2000). The Invention of Modern Science. Minneapolis: University of Minnesota Press.

Wade, K.A., M. Garry, J.D. Read and D.S. Lindsay (2002). A picture is worth a thousand lies: Using false photographs to create false childhood memories. Psychonomic Bulletin \& Review, 9, 597-603.

Weiner, N. (1948). Cybernetics: Or Control and Communication in Animal and Machine. Cambridge, Mass: The MIT Press. 